\title{
Retrospective Analysis of Patients with Post-Tonsillectomy Hemorrhage in a University Hospital \\ Merih Onal
}

Assistant Professor, Selcuk University Medical Faculty, Department of Otorhinolaryngology, Konya, Turkey

DOI: $10.36347 /$ sjams.2020.v08i12.040

| Received: 27.11.2020 | Accepted: 21.12.2020 | Published: 30.12.2020

*Corresponding author: Merih Onal

E-mail: drmerihonal@gmail.com

Abstract

Original Research Article

Background/Aim: Tonsillectomy is one of the most common surgical procedures performed by otolaryngologists. Recurrent/ chronic tonsillitis and sleep disorders due to tonsillar hypertrophy are among the most common indications for tonsillectomy. Although complications such as pain, dehydration, airway obstruction, sleep disorders, and pulmonary edema may occur after tonsillectomy, the most common life-threatening complication is post-tonsillectomy hemorrhage (PTH). In our study, we aimed to help clinicians with this potentially fatal complication by retrospectively examining the characteristics of patients with PTH and the management of PTH treatment. Materials and Methods: Twenty-five patients who underwent a tonsillectomy in a university hospital between 2011-2020, who was diagnosed with PTH, and whose bleeding was surgically controlled were included in the study. In addition to the demographic data of these patients, tonsil size, tonsillectomy surgery technique, postoperative bleeding location, postoperative bleeding day, and the technique of surgery for PTH treatment were examined. Results: The incidence of PTH was found to be $1.1 \%$ in patients who underwent tonsillectomy. Five patients (20\%) had a primary hemorrhage and 20 patients $(80 \%)$ had a secondary hemorrhage. The most common tonsillectomy method was the cold blade dissection method with a rate of $88 \%$, and the most commonly used method in bleeding control was bipolar cauterization with a rate of $76 \%$ regardless of suturing. Conclusion: Although new developments in tonsil surgery and surgical instruments have come into use, the method of cold blade dissection is still seen as the most commonly used method. Suturing with bipolar cauterization used in the treatment of PTH that occurs after tonsillectomy surgery provides effective success.

Keywords: Palatine tonsils; tonsillectomy; complication; postoperative hemorrhage; electrocoagulation.

Copyright $\left({ }_{0} 2020\right.$ The Author(s): This is an open-access article distributed under the terms of the Creative Commons Attribution 4.0 International License (CC BY-NC 4.0) which permits unrestricted use, distribution, and reproduction in any medium for non-commercial use provided the original author and source are credited.

\section{INTRODUCTION}

Tonsillectomy is one of the most commonly performed surgery all over the world, especially in pediatric patients. Tonsillectomy is primarily indicated in cases of recurrent tonsillitis or tonsillar hypertrophy, leading to airway obstruction and sleep disorders. In tonsillectomy surgery, the tonsil and its capsule is removed en bloc by being dissected from the muscular wall in peritonsillar space. Subsequently, the tonsillar fossa, which is the region from which tonsils are removed, heals secondarily. Blood supply of tonsillar structure is from many vascular structures originating from the external carotid artery and tonsillar venous plexus. The source of bleeding in the tonsillar fossa after tonsillectomy is this rich vascular structure, and this condition is termed post-tonsillectomy hemorrhage (PTH). PTH is one of the most common and lifethreatening complications following tonsillectomy [1]. Depending on the definition of PTH, the incidence varies between $0.2-40 \%$ and the mortality rate is
1:20.000 [2-5]. PTH's following tonsillectomy procedures are divided into two groups according to the time of their onset. Primary bleeding occurs $(0.2 \%$ $2.2 \%$ ) within first 24 hours postoperatively, while secondary bleeding $(0.1 \%-4.8 \%)$ occurs after postoperative 24 hours [3-5].

Advanced age is the most important factor determining both the incidence of PTH and the difficulty of controlling it. The highest incidence of PTH occurs between the ages of 11-17 and PTH control is more challenging in children over the age of 6 than in children under the age of 6 [6-9]. Tonsillectomy surgery may be carried out with many different techniques. In the cold knife dissection technique, tonsils are dissected from the fossa with an elevator, and hemostasis is provided by the exertion of direct pressure, suture, or chemical cauterization. In hot techniques, various electrosurgical and thermal devices are utilized in order to remove tonsillar tissue and provide hemostasis [10]. Although cold techniques are associated with a lower 
incidence of hemorrhage, hot techniques are not an independent risk factor for PTH on their own [11,12]. Patients diagnosed with PTH are usually hospitalized and bleeding is controlled with surgical intervention. However, PTH is unpredictable for clinicians and may be life-threatening for patients. Therefore, factors affecting its etiopathogenesis should be completely elucidated in order that PTH may be prevented before arising or may be treated without risking the patient's life. The aim of this study was to evaluate the files of patients who applied with PTH in the last 9 years and provide guiding information to clinicians on this issue.

\section{MATERIAL AND MeTHOD}

After approval was obtained from the ethics committee of Selcuk University Faculty of Medicine (2020/402), files of patients who underwent treatment in our Ear-Nose-Throat Clinic with the diagnosis of PTH between 2011-2020 were retrospectively investigated. Of 2112 patients who underwent tonsillectomy for chronic and recurrent tonsillitis and tonsillar hypertrophy irrespective of adenoidectomy, 25 patients in pediatric and adult age groups who were hospitalized with the diagnosis of PTH and whose bleeding was controlled with surgical interventions were included in the present study. Patients with a clotting disorder, nutritional deficiency, malignity, or problems associated with any syndrome were excluded from the study. In addition to demographic data of patients included in the study, tonsil size, tonsillectomy technique used, location of post-tonsillectomy bleeding, the day of bleeding, and surgical intervention technique used to control PTH were all recorded. The same general anesthesia technique and agents were used in all patients and PTH was defined as bleeding arising after the end of tonsillectomy surgery and extubation.

\section{RESULTS}

Overall 25 patients ( 9 female, 16 male) were included in the present study. Twelve patients (19-36 years) were in the adult age group while 13 were (3-18 years) in the pediatric age group. Their mean age was $17.6 \pm 11.4$. In tonsillectomy surgery, cold knife dissection technique was used in 22 patients (88\%), PlasmaBlade ${ }^{\mathrm{TM}}$ (Medtronic, Minneapolis, ABD) coagulation knife was used in 2 patients (8\%), and LigaSure $^{\mathrm{TM}}$ (Medtronic, Minneapolis, ABD) vessel closing system was used in 1 patient (4\%) (Table 1). Bleeding was detected in the right tonsillar fossa in 7 patients $(28 \%)$, in the left tonsillar fossa in 10 patients $(40 \%)$, and in both fossas $(32 \%)$ in 8 patients. According to the Friedmann staging system, tonsil size was established to be at stage 2 in 7 patients, stage 3 in 16 patients, and stage 4 in 2 patients [13] (Table 1). PTH incidence was found to be $1.1 \%$ in the present study, with 5 patients $(20 \%)$ having primary hemorrhage and 20 patients $(80 \%)$ having secondary hemorrhage (Table 2). In all of the patients followed with primary hemorrhage, the cold knife dissection technique was used in surgery. Bleeding control after tonsillectomy surgery was carried out with bipolar cauterization along with suture in 11 patients, bipolar cauterization alone in 8 patients, and suture alone in 6 patients (Table 2). PTH emerged at mean postoperative $7.04 \pm 5.1$ days. The earliest time of bleeding was the 4th hour while the latest time of bleeding was the 18th day postoperatively.

Table-1: Tonsilllar size stages and surgical methods used in patients undergoing tonsillectomy

\begin{tabular}{|l|l|l|l|l|l|l|l|}
\hline & $\begin{array}{l}\text { Overall number of patients } \\
(\mathbf{n})\end{array}$ & stage 2 & Stage 3 & Stage 4 & Cold knife & LigaSure $^{\text {TM }}$ & $\begin{array}{l}\text { Plasma } \\
\text { Blade }^{\mathbf{T M}}\end{array}$ \\
\hline Adult & 12 & 5 & 7 & 0 & 11 & 1 & 0 \\
\hline Children & 13 & 2 & 9 & 2 & 11 & 0 & 2 \\
\hline
\end{tabular}

Table-2: In patients with primary and secondary hemorrage and methods used in bleeding control

\begin{tabular}{|l|l|l|l|l|l|l|}
\hline & $\begin{array}{l}\text { Bipolar + } \\
\text { suture (n) }\end{array}$ & $\begin{array}{l}\text { Suture } \\
(\mathbf{n})\end{array}$ & $\begin{array}{l}\text { Bipolar } \\
(\mathbf{n})\end{array}$ & $\begin{array}{l}\text { Mean time of } \\
\text { occurrence } \\
(\text { days ) }\end{array}$ & $\begin{array}{l}\text { Primary } \\
\text { hemorrhage } \\
(\mathbf{n})\end{array}$ & $\begin{array}{l}\text { Secondary } \\
\text { hemorrhage } \\
(\mathbf{n})\end{array}$ \\
\hline Adult & 6 & 4 & 2 & 6.8 & 2 & 10 \\
\hline children & 5 & 2 & 6 & 7.7 & 3 & 10 \\
\hline
\end{tabular}

\section{DISCUSSION}

In many studies on bleeding after tonsillectomy, the incidence rate of PTH was found to vary between $0.2 \%$ and $40 \%$ depending on the definition of PTH used [2-5]. English National Prospective Tonsillectomy Audit (NPTA) evaluated around 12000 patients and found the rate of PTH to be $3.3 \%$, with $0.5 \%$ primary and $2.8 \%$ secondary hemorrhage (14). In the study of Saravakos et al., it was demonstrated that of 1007 patients included in the study, $116(11.5 \%)$ had postoperative bleeding [15]. In their study, solely patients with chronic tonsillitis, acute tonsillitis, and peritonsillar abscess as surgery indications were included in the study. Patients with tonsillar hypertrophy were excluded. In the present study, of 2112 tonsillectomy patients, 25 experienced postoperative bleeding, and the rate of PTH was found to be $1.1 \%$. Patients who underwent tonsillectomy due to tonsillar hypertrophy were included in the present study in addition to those undergoing surgery for chronic/ recurrent tonsillitis irrespective of adenoidectomy. The inclusion of patients who 
underwent tonsillectomy owing to tonsil hypertrophy in the present study may account for the lower rate of PTH compared to the aforementioned study.

In the study of Kim et al. the rate of PTH was reported to be $3.1 \%$ in children under 11 years old, $2.5 \%$ in $12-15$ age group children, and $10.8 \%$ in patients over the age of 15 [16]. Accordingly, adult age groups seem to be the patient group that is most susceptible to bleeding. Our results were consistent with those of the aforementioned study, as $36 \%$ of our patients were under the age of $6,8 \%$ between the ages of $6-18$, and $56 \%$ adults over the age of 18 . Similarly, in the study of Akın et al., it was reported that the risk of PTH was approximately 2.5 fold higher in patients over the age of 40 than patients under the age of 40 [17]. It was thought that the reason why intraoperative and postoperative bleeding occurs more commonly in adults may be that blood supply may have become richer due to marked scar tissue following long term inflammation with advanced age, fibrosis developing in the peritonsillar region and to increase in the diameter of blood vessels [18].

One of the most important stages of tonsillectomy surgery is the dissection of the lower pole of the tonsil, where bleeding occurs most commonly in PTH [19]. Hence, care should be taken to control bleeding in the lower pole while removing the tonsil. In order to prevent bleeding in this region, it was recommended that a suture should be applied to the part of the lower pole of the tonsil which is near to the root of the tongue. In the present study, during tonsillectomy surgery, the suture was not applied routinely to the root of the tongue. However, in patients with postoperative bleeding, suture in combination with cauterization is a commonly performed procedure. Excessive excision of tonsil tissue near tongue root leads to postoperative bleeding whilst its inadequate excision leads to residual tonsil tissue or hypertrophy of tonsil again. Nevertheless, it should be kept in mind that transoral suture placement may injure a larger vessel coursing near a surgical wound. In another study, it was suggested that a suture placed to the root of the tongue during tonsillectomy may cause external carotid artery injury and that efficient use of electrocautery instead of the suture may prevent this [20]. Therefore, if suture placement to tonsillar fossa is being planned after tonsillectomy, it should be deep enough to stop bleeding, but not too deep to reach the great vessels.

No doubt, one of the most important determinants of post-tonsillectomy bleeding is the method used in tonsillectomy. In the study of Walker et al., it was reported that cold knife dissection along with suture was the technique with the lowest risk of PTH [21]. They stated that if they consider the probability of post-tonsillectomy bleeding with this technique as 1 , this rate has been found to be 1.6 if monopolar or bipolar cauterization is used together with cold knife dissection and 2.5-3.2 if only monopolar or bipolar cauterization is used. In addition, bipolar cauterization leads to PTH in the late period, increasing mortality, while in the cold knife dissection method, PTH occurs in an earlier period [22]. Actually in the present study, in all primary hemorrhage cases (5 patients), bipolar cauterization in addition to cold knife dissection was used.

When these cases underwent surgery again for bleeding control, hemostasis was provided with only bipolar cauterization in 3 patients and with cauterization in combination with suture in the remaining two patients. The general approach in our clinic is to use sutures for bleeding control if hemostasis is not possible with bipolar cauterization. Conversely, in the NPTA study, the suture was tried first to control bleeding and if was not effective, bipolar cauterization was performed [14]. Our clinical experience has demonstrated that excessive cauterization does not control bleeding points after a certain stage, on the contrary, it further aggravates bleeding. At this point, using suture seems to be more effective. In order to prevent excessive tissue trauma and delayed wound healing in our patients, for hemostasis we use bipolar electrocauterization for a short period and at low doses, as recommended by Soy et al. [23].

\section{Conclusion}

This study has some limitations such as retrospective design and the absence of randomized control groups. However, evaluating the cases diagnosed with PTH in a tertiary university hospital will guide clinicians in terms of both preventing this lifethreatening situation and making it easier to decide on the ideal treatment method when it occurs. Further studies on this complication will increase our knowledge and guide us in patient management.

\section{REFERENCES}

1. Wall JJ, Tay K-Y. Postoperative tonsillectomy hemorrhage. Emerg Med Clin. 2018;36(2):415-26.

2. Krishna P, Lee D. Post-tonsillectomy bleeding: a meta-analysis. Laryngoscope 2001;111(8):13581361.

3. Francis DO, Fonnesbeck C, Sathe N, McPheeters M, Krishnaswami S, Chinnadurai S. Postoperative bleeding and associ-ated utilization following tonsillectomy in children: a systematic review and meta-analysis. Otolaryngol Head Neck Surg. 2017; 156(3): 442-55.

4. Windfuhr JP, Chen YS, Remmert S. Hemorrhage following tonsillectomy and ad-enoidectomy in 15,218 patients. Otolaryngol Head Neck Surg. 2005;132(2): 281-6.

5. Baugh RF, Archer SM, Mitchell RB. Clinical practice guideline: tonsillectomy in children. Otolaryngol Head Neck Surg. 2011; 144: 1-30. 
6. Lee WT, Witsell DL, Parham K. Tonsillectomy bleed rates across the CHEER Practice Research Network. Otolaryngol Head Neck Surg. 2016;155(1):28-32.

7. Spektor Z, Saint-Victor S, Kay DJ, Mandell DL. Risk factors for pediatric post-tonsillectomy hemorrhage. Int J Pediatr Otorhinolaryngol. 2016; 84: 151-5

8. Harounian JA, Schaefer E, Schubart J, Carr MM. Pediatric adenotonsillectomy and postoperative hemorrhage: demographic and geographic variation in the US. Int J Pediatr Otorhinolaryngol. 2016; 87 : $50-4$.

9. Arora R, Saraiya S, Niu X, Thomas RL, Kannikeswaran N. Post tonsillectomy hemorrhage: who needs inter-vention? Int $\mathrm{J}$ Pediatr Otorhinolaryngol. 2015; 79(2): 165-9.

10. Magdalena ML, Sole' A, Blanco V, Rodrigo JP. Histological analysis of tonsillectomies: relationship with surgical technique, post-operative pain and haemorrhage. J Laryngol Otol. 2016; 130(12):1142-6.

11. Hinton-Bayre AD, Noonan $\mathrm{K}$, Ling $\mathrm{S}$, Vijayasekaran S. Experience is more important than technology in paediatric post-tonsillectomy bleeding. J Laryngol Otol. 2017; 131: 35-40.

12. Walner DL, Karas A. Standardization of reporting posttonsillectomy bleeding. Ann Otol Rhinol Laryngol. 2013;122(4):277-282.

13. Friedman M, Tanyeri H, La Rosa M, Landsberg R, Vaidyanathan K, Pieri S, et al. Clinical predictors of obstructive sleep apnea. Laryngoscope. 1999; 109: 1901-1907.
14. Brown P, Ryan R, Yung M. Ramsden, National Prospective Tonsillectomy Audit, Royal College of Surgeon; 2005.

15. Saravakos $P$, Hartwein J. Surgical technique and post-tonsillectomy hemorrhage: a single institution's retrospective study. Eur Arch Otorhinolaryngol. 2017; 274:947-952.

16. Kim DW, Koo JW, Ahn SH, Lee CH, Kim JW. Difference of delayed post-tonsillectomy bleeding between children and adults. Auris Nasus Larynx. 2010; 37: 456-60.

17. Akin RC, Holst R, Schousboe LP. Risk factors for post-tonsillectomy haemorrhage. Acta Otolaryngol. 2012; 132:773-7.

18. Windfuhr JP, Chen YS. Post-tonsillectomy and adenoidectomy hemorrhage in nonselected patients Ann Otol Rhinol Laryngol. 2003; 112:63-70.

19. Burton K, Hanke S, Gungor. Reduced posttonsillectomy bleeding rates through a refined technique. Am J Otolaryngol. 2017; 38:438-41.

20. Schmidt H, Schmiz A, Stasche N, Hörmann K. Surgically managed postoperative hemorrhage after tonsillectomy. Laryngorhinootologie. 1996; 75(8):447-454.

21. Walker P, Gillies D. Post-tonsillectomy hemorrhage rates: Are they technique-dependent? Otolaryngol Head Neck Surg. 2007; 136:27-31.

22. Gysin C, Dulguerov P. Hemorrhage after tonsillectomy: does the surgical technique really matter? ORL J Otorhinolaryngol Relat Spec. 2013; 75(3):123-132.

23. Soy FK, Dündar R, Yazıcı H, Kulduk E, Aslan M, Sakarya U. Bipolar cautery tonsillectomy using different energy doses: pain and bleeding. Int $\mathbf{J}$ Pediatr Otorhinolaryngol. 2014; 78(3): 402-406. 